\title{
A silicon condenser microphone with polyimide diaphragm and backplate
}

\author{
Michael Pedersen *, Wouter Olthuis, Piet Bergveld \\ MESA Research Institute, University of Twente, $\overline{P O}$ Box $217, N L-7500$ AE Enschede, Netherlands
}

Received 28 August 1996; revised 10 February 1997; accepted 2 March 1997

\begin{abstract}
A new technology for the fabrication of silicon condenser microphones is presented. The technology, which is based on the use of polyimide, can be performed entirely as a post process on substrates already containing integrated circuits. Microphones with an open-circuit sensitivity of $8.1 \mathrm{mV} \mathrm{Pa}^{-1}$, and a flat frequency response $( \pm 2 \mathrm{~dB}$ ) between $100 \mathrm{~Hz}$ and $15 \mathrm{kHz}$ have been fabricated with this technology. The bias voltage used in these measurements is $15 \mathrm{~V}$, and the measured noise level with zero bias is $24 \mathrm{~dB}$ SPL, which is sufficient for most acoustic applications, including hearing aids. (C) 1997 Elsevier Science S.A.
\end{abstract}

Keywords: Silicon condenser microphones; Polyimide; IC-compatible sensors

\section{Introduction}

The condenser microphone is one of the classical capacitive sensors, of which few devices have been presented with on-chip detection circuitry [1,2]. Even though the advantages of integration, notably smaller parasitic capacitances, higher sensitivity [2], and lower noise generation [3], are desirable, the silicon condenser microphones prove difficult to combine with electronic fabrication technologies. Ever since the first developments of silicon-based condenser microphone structures, by Hohm and Hess [4], efforts have been made to improve the performance and flexibility of these devices. The result has been the evolution of several different microphone structures [5-9]. Common for all these designs is the small air gap between the diaphragm and the backplate, whereby the required d.c. bias voltage $\left(V_{b}\right)$ has been reduced from $>100 \mathrm{~V}$ to $10-20 \mathrm{~V}$. However, since all these devices consist of two separately processed parts, which are later bonded or glued together, they are considered to be less suitable for integration with electronic circuitry. One of the first condenser microphones made on a single chip was presented by Scheeper et al. [10]. This design comprised a thin-film diaphragm and backplate made with a combined bulk- and surface-micromachining process. Later, condenser microphones with a similar structure, but with different thin-film materials were demonstrated $[1,11,12]$.

\footnotetext{
* Corresponding author. Phone: + 31534892722 . Fax: + 31534892287. E-mail:psn@eltn.utwente.nl
}

In this paper, a new condenser microphone structure is presented. The structural design is similar to that of Scheeper et al. [10], however, the materials and the fabrication process are different. Since the fabrication process only consists of low-temperature $\left(<300^{\circ} \mathrm{C}\right)$ spin-on, baking, evaporation and etching processes, it is believed that the process may be performed as a post-process on substrates where electronic circuits have already been completed. The advantage of this approach is that the structures can be integrated with any electronic process, without any adaptation required of the complex IC fabrication process. In the following it will be shown that the introduction and use of polyimide for the mechanical parts of the microphone improves the IC compatibility of the whole fabrication process. Polyimide has previously been applied in micromechanical structures $[13,14]$, and polymer diaphragms have already been applied in silicon electret microphones by Sprenkels et al. [15].

\section{Device technology}

The microphone structure (Fig. 1) is in principle similar to that of Scheeper et al. [10], where the backplate is placed

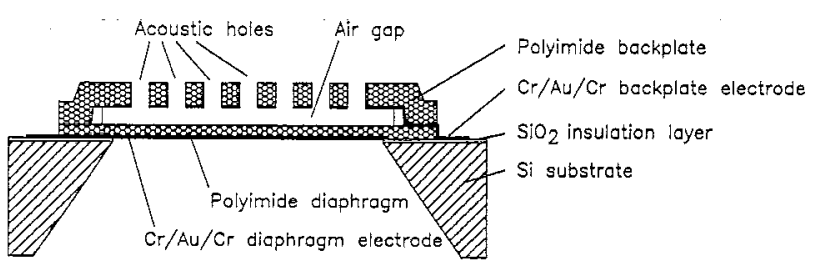

Fig. 1. Cross-sectional view of a condenser microphone with polyimide membrane and backplate. 
on top of the diaphragm with a sacrificial layer in between, which is etched away to create the air gap, and where the etch holes in the backplate function as the necessary acoustic holes in the finished microphone.

In contrast to previous designs of this structure, the diaphragm and backplate are made of a polymer (polyimide). The use of this material offers several advantages over more conventional micromechanical materials. First, and most important, the processing of the material is very simple. If a photosensitive polyimide is used, the process of deposition and patterning is like a conventional lithographic process followed by a low-temperature $\left(300^{\circ} \mathrm{C}\right)$ curing of the polyimide. Secondly, the polyimide can be made with thicknesses from $<1 \mu \mathrm{m}$ to $>30 \mu \mathrm{m}$, which makes it possible to produce thin diaphragms as well as thicker backplates with one and the same technology. The lack of this possibility has until now been one of the problems of the single-chip microphone structure. By placing the backplate electrode under the backplate, problems with step coverage over the thick backplate can be eliminated. Lastly, the polyimide layers can generally be made with lower built-in stress than conventional materials, yielding microphones with higher sensitivities.

For the metal electrodes in the structure, $\mathrm{Cr} / \mathrm{Au} / \mathrm{Cr}$ multilayers were chosen. These layers comprise the good combination of the relatively low stress of Au and the supreme adhesion of Cr on polyimide [16]. Since the cured polyimide is chemically very stable in acid solutions, layers of $\mathrm{Al}$ or $\mathrm{Ag}$ may be used for the sacrificial layer, and subsequently etched very selectively. The etching of the silicon substrate is first carried out with $\mathrm{KOH}$, until $\approx 50 \mu \mathrm{m}$ of silicon remains in the sensor area. The remaining silicon is then etched with reactive ion etching (RIE), where the $\mathrm{Cr} / \mathrm{Au} / \mathrm{Cr}$ diaphragm electrode acts as an etch stop.

\section{Theory of operation}

The normal way to operate the condenser microphone is to apply an electrical field between the diaphragm and the backplate, by means of a d.c. bias voltage. Consequently, any movement of the diaphragm with respect to the backplate may be detected as a change of potential across the microphone.

\subsection{Dynamic model}

The dynamic properties of the transducer can be derived by applying the analogy between the acoustic, mechanical and electrical domains [17], and the mechanical equivalent circuit is shown in Fig. 2. The mechanical source represents

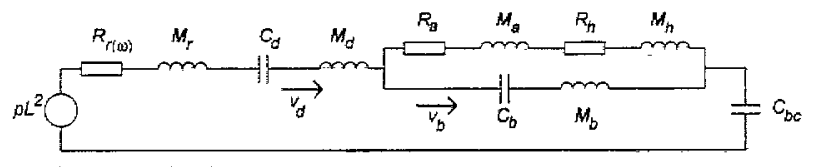

Fig. 2. Mechanical equivalent circuit of the condenser microphone. the force applied by the harmonic sound pressure $p$, acting on the square diaphragm with side length $L$. The mechanical resistance $R_{\mathrm{r}(\omega)}$ and inductance $M_{\mathrm{r}}$ account for the radiation impedance of the diaphragm, and are given by

$R_{\mathrm{r}\{\omega\}}=\frac{0.1886}{\pi^{3}} \frac{L^{6} \rho_{0} \omega}{c^{3}} \quad M_{\mathrm{r}}=\frac{2.67 L^{3} \rho_{0}}{\pi \sqrt{\pi}}$

where $\rho_{0}$ is the density of air, $\omega$ is the angular frequency and $c$ is the speed of sound in air.

If the flexural rigidity of the diaphragm and the backplate is assumed to be dominated by the intrinsic stress, the compliances $C_{\mathrm{d}}$ and $C_{\mathrm{b}}$ are defined as

$$
C_{\mathrm{d}}=\frac{1}{30 \sigma_{\mathrm{d}} h_{\mathrm{d}}} \quad C_{\mathrm{b}}=\frac{1}{30 \sigma_{\mathrm{b}} h_{\mathrm{b}} \sqrt{1-\frac{4 a^{2}}{b^{2}}}}
$$

in which the $\sigma_{\mathrm{d}}, \sigma_{\mathrm{b}}$ and $h_{\mathrm{d}}, h_{\mathrm{b}}$ are intrinsic stresses and thicknesses of the diaphragm and the backplate, and $2 a$ and $b$ are the size and centre-to-centre distance of the acoustic holes in the backplate. The mass of the diaphragm and the backplate are given by

$M_{\mathrm{d}}=\rho_{\mathrm{d}} h_{\mathrm{d}} L^{2} \quad M_{\mathrm{b}}=\rho_{\mathrm{b}} h_{\mathrm{b}} L^{2} \sqrt{1-\frac{4 a^{2}}{b^{2}}}$

where $\rho_{\mathrm{d}}$ and $\rho_{\mathrm{b}}$ are the densities of the diaphragm and the backplate.

The mechanical impedance caused by air streaming in the narrow air gap between the diaphragm and the backplate has been derived by Skvor [18] for a non-compressible laminar flow and is given by

$R_{\mathrm{a}}=\frac{1.22 \eta \pi L^{2} b^{2}}{h_{\mathrm{a}}^{3}} B \quad M_{\mathrm{a}}=\frac{0.102 \rho_{0} \pi L^{2} b^{2}}{h_{\mathrm{a}}} B$

where $\eta$ is the dynamic viscosity of air, $h_{\mathrm{a}}$ is the height of the air gap, and $B$ is defined as

$B=\frac{1}{4} \ln \left(\frac{0.160 b^{2}}{a^{2}}\right)-\frac{3}{8}+3.133 \frac{a^{2}}{b^{2}}-4.907 \frac{a^{4}}{b^{4}}$

Furthermore, the streaming of air in the acoustic holes in the backplate causes an impedance described by $R_{\mathrm{h}}$ and $M_{\mathrm{h}}$. By considering the holes as narrow slits [19], this impedance can be expressed by

$R_{\mathrm{h}}=\frac{12 \eta h_{\mathrm{b}} L^{2}}{b^{2}} \quad M_{\mathrm{h}}=\frac{24 \rho_{\mathrm{u}} h_{\mathrm{b}} a^{2} L^{2}}{5 b^{2}}$

The enclosed volume in the backchamber, which is required to provide the dynamic pressure difference across the diaphragm, gives rise to the mechanical compliance $C_{\mathrm{bc}}$. If the air in the backchamber is assumed to be an ideal gas, the compliance is given by [19]

$C_{\mathrm{bc}}=\frac{V}{\rho_{0} c^{2} L^{4}}$ 


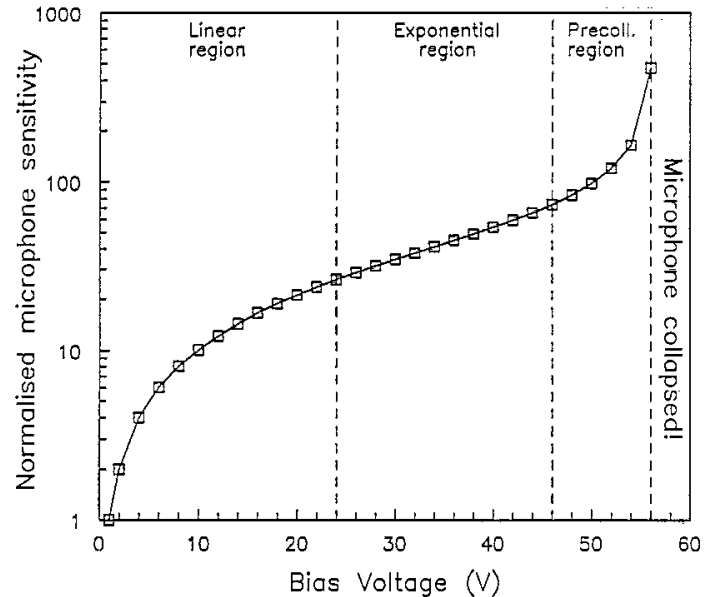

Fig. 3. Typical result of the quasistatic analysis. Normalized sensitivity vs. d.c. bias voltage.

where $V$ is the volume of the backchamber. In the measurements presented later in this paper, however, the volume, and consequently the compliance of the backchamber, was assumed to be infinitely large.

By calculating the flows $v_{\mathrm{d}}$ and $v_{\mathrm{b}}$ in the mechanical equivalent circuit, the velocities of the diaphragm and the backplate may be determined. If the applied sound pressure is harmonic, the displacement of the diaphragm and backplate can be derived simply by dividing the velocities by the angular frequency $\omega$. For frequencies below the resonance frequencies of the diaphragm and the backplate, the two displacements will be in phase and must consequently be subtracted to attain the effective variation of the air gap $x_{\mathrm{a}}$. The output signal of the microphone is calculated by multiplying the electrical field in the air gap by the differential displacement:

$v_{\text {out }}=E x_{\mathrm{a}}=E\left(x_{\mathrm{d}}-x_{\mathrm{b}}\right)=E \frac{v_{\mathrm{d}}-v_{\mathrm{b}}}{\omega}$

Considering the structure in Fig. 1, the effective electrical field in the air gap is given by

$E=K \frac{\epsilon_{\mathrm{d}} V_{\text {bias }}}{\epsilon_{\mathrm{d}} h_{\mathrm{a}}+h_{\mathrm{d}}}$

where $\epsilon_{d}$ is the relative dielectric constant of the diaphragm material, $V_{\text {bias }}$ is the applied bias voltage and $K$ is a factor accounting for the field reduction due to the holes in the backplate. The sensitivity of the microphone is given by dividing the output signal by the applied acoustic sound pressure, yielding the following expression:

$S=\frac{v_{\text {out }}}{p}=K \frac{\epsilon_{\mathrm{d}}\left(v_{\mathrm{d}}-v_{\mathrm{b}}\right)}{p \omega\left(\epsilon_{\mathrm{d}} h_{\mathrm{a}}+h_{\mathrm{d}}\right)} V_{\text {bias }}$

\subsection{Quiasistatic model}

Another important aspect of the condenser microphone is the stability. The problem of stability is mainly caused by the electrostatic forces induced by the bias voltage. This attraction force between the diaphragm and the backplate may cause a collapse of the structure if the bias voltage or consequently the electrical field is too high. The stability of this non-linear system can be analysed in the quasistatic situation for frequencies far below roll-off and/or resonances, where the deflection of the diaphragm and the backplate can be described by a non-linear coupled differential equation system [20], the stability of which coincides with the stability of the microphone. A detailed description of the theory and simulation of this system can be found elsewhere in the literature [20,21], and will only be illustrated here by a typical result of such an analysis. In Fig. 3, the normalized quasistatic sensitivity is shown as function of the applied d.c. bias voltage. As can be seen, it is possible to divide the mode of operation into four different regions. In the first linear region, the electrostatic forces are insignificant and the sensitivity consequently increases linearly with the increase of the electrical field. In the exponential region the electrostatic forces become more significant, causing an exponential dependence of the sensitivity on the bias voltage. For higher voltages in the pre-collapse region, the electrostatic forces are very dominating, whereby the dependence becomes stronger than exponential. Finally, above the critical bias voltage the structure collapses, and no solution to the quasistatic equation system exists.

The material parameters and dimensions of the two realized microphone structures are given in Table 1, and the behaviour has been simulated with both the dynamic and quasistatic models. The built-in stress in the polyimide was

Table 1

Material parameters and microphone dimensions

Young's modulus (diaphragm/backplate)

Poisson's ratio (diaphragm/backplate)

Density (diaphragm/backplate)

Relative dielectric constant (diaphragm)

Intrinsic stress in diaphragm

Intrinsic stress in backplate

Thickness of diaphragm

Thickness of backplate

Air gap

Side length

Acoustic hole size in backplate

Acoustic hole fraction in backplate

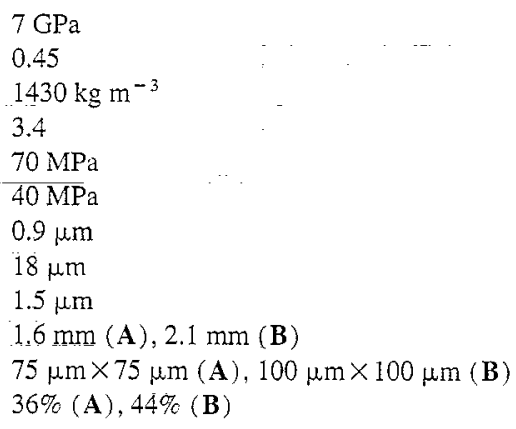


measured separately with the wafer bending method, from which a tensile stress of $40 \mathrm{MPa}$ was determined. In the thin polyimide diaphragm, the tensile stress in the $\mathrm{Cr} / \mathrm{Au} / \mathrm{Cr}$ electrode layer is also significant, and has been measured to be as high as $1 \mathrm{GPa}$. For a $0.9 \mu \mathrm{m}$ thick polyimide diaphragm with a $30 \mathrm{~nm}$ thick $\mathrm{Cr} / \mathrm{Au} / \mathrm{Cr}$ electrode, this yields an overall stress of approximately $70 \mathrm{MPa}$. In Fig. 4, the simulated dynamic response of the two microphones is shown for a d.c. bias voltage of $15 \mathrm{~V}$. It can be seen that both responses are flat in the frequency range between $100 \mathrm{~Hz}$ and $15 \mathrm{kHz}$, which implies that the hole fraction in the backplate is sufficient. From the calculations open-circuit sensitivities of -44.1 $\mathrm{dBV} \mathrm{Pa}{ }^{-1}\left(6.2 \mathrm{mV} \mathrm{Pa}^{-1}\right)$ and $40.2 \mathrm{dBV} \mathrm{Pa}^{-1}(9.8 \mathrm{mV}$ $\mathrm{Pa}^{-1}$ ) are predicted for type $\mathbf{A}$ and $\mathbf{B}$, respectively. Furthermore, the resonance frequencies of the diaphragm and the backplate were calculated to be 91.3 and $100.0 \mathrm{kHz}$ for type $\mathbf{A}$, and 66.3 and $77.8 \mathrm{kHz}$ for type $\mathbf{B}$. The open-circuit sensitivity was also simulated as a function of the d.c. bias voltage with the quasistatic model, yielding the curves in Fig. 5 . From these simulations a critical bias voltage of $23.5 \mathrm{~V}$ for type $\mathbf{A}$ and $19.0 \mathrm{~V}$ for type $\mathbf{B}$ was calculated.

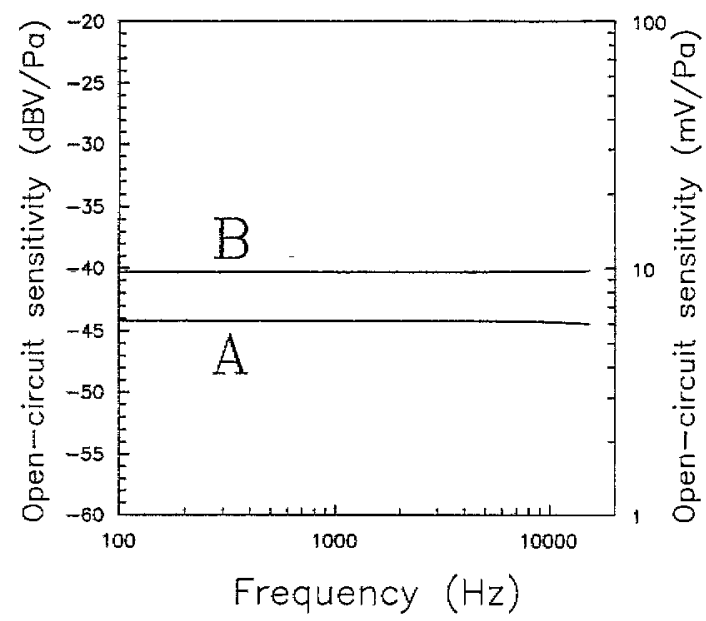

Fig. 4. Simulated frequency response of the two polyimide condenser microphones (A: $1.6 \mathrm{~mm}, \mathbf{B}: 2.1 \mathrm{~mm}$ ) with $V_{\text {bias }}=15 \mathrm{~V}$.

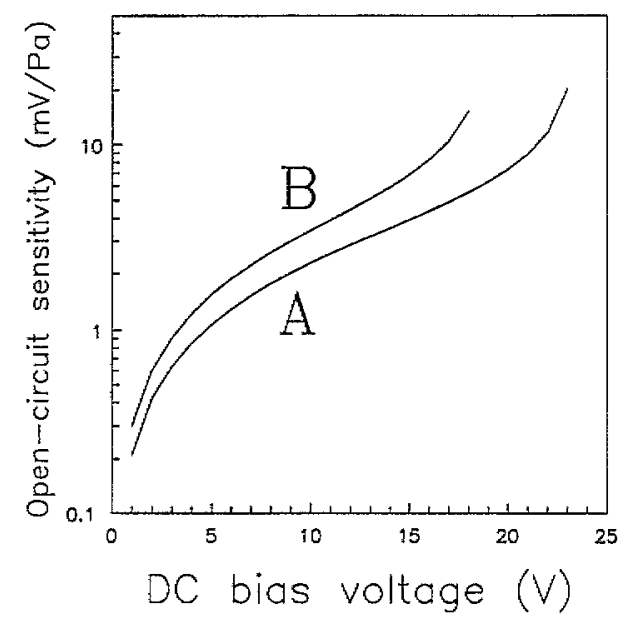

Fig. 5. Simulated open-circuit sensitivity vs. d.c. bias voltage for the two polyimide condenser microphones (A: $1.6 \mathrm{~mm}$, B: $2.1 \mathrm{~mm}$ ).

\section{Device fabrication}

Microphones have been fabricated using the process shown in Fig. 6. The silicon substrates used were $3^{\prime \prime},\langle 100\rangle$, p-type, $5 \Omega \mathrm{cm}$ wafers. The thickness of the substrates was $400 \mu \mathrm{m}$. First, a $1.5 \mu \mathrm{m}$ thick layer of $\mathrm{SiO}_{2}$ was grown by wet oxidation at $1150^{\circ} \mathrm{C}$. The $\mathrm{SiO}_{2}$ was subsequently etched in BHF to define the active sensor area on the backside of the substrate. During the etching, the front was protected with photoresist. The substrate was then etched in a $\mathrm{KOH}$ solution ( $33 \mathrm{wt} . \%$, $73^{\circ} \mathrm{C}$ ) until the thickness in the sensor area was reduced to approximately $50 \mu \mathrm{m}$ (Fig. 6(a)). After rinsing, a thin diaphragm electrode was evaporated and patterned on the front, using a standard lift-off process with photoresist. The electrode was a $\mathrm{Cr} / \mathrm{Au} / \mathrm{Cr}$ multilayer, with a thickness of $4 / 20$ / $4 \mathrm{~nm}$.

The first layer of polyimide, which is later to be the diaphragm, was then spun on the front. The photosensitive polyimide was HTR3-200 from OCG Microelectronics, and in order to obtain a sufficiently thin layer, a 5:1 solution of polyimide and the solvent NMP ( $N$-methylpyrrolidone) was used. To improve the adhesion on the $\mathrm{SiO}_{2}$ surface, a $\gamma$-APS (aminopropyltriethoxysilane) promoter was applied before the spinning of the polyimide. For the polyimide layer, a speed of $4000 \mathrm{rpm}$ and a time of $1 \mathrm{~min}$ were used, yielding a layer with an approximate thickness of $1 \mu \mathrm{m}$. After a prebake for $25 \mathrm{~min}$ at $90^{\circ} \mathrm{C}$ to remove the solvent, the layer was exposed to $350 \mathrm{~nm}$ UV light with an energy of $15 \mathrm{~mW} \mathrm{~cm} \mathrm{~cm}^{-2}$ for $15 \mathrm{~s}$, and baked for $10 \mathrm{~min}$ at $90^{\circ} \mathrm{C}$. This intermediate bake was done to enhance the prepolymerization of the exposed areas. Thereafter, the layer was developed for $1 \mathrm{~min}$ in HTRD-3 polyimide developer from OCG Microelectronics, and subsequently rinsed in IPA (isopropyl alcohol). The polyimide was then cured for $1 \mathrm{~h}$ at $300^{\circ} \mathrm{C}$ in an $\mathrm{N}_{2}$ atmosphere, and the thickness of the polyimide diaphragm was measured with a SLOAN-DEKTAK Surface Profiler to be $0.8-0.9 \mu \mathrm{m}$. An Al sacrificial layer was then deposited and patterned, using electron-beam evaporation and a standard
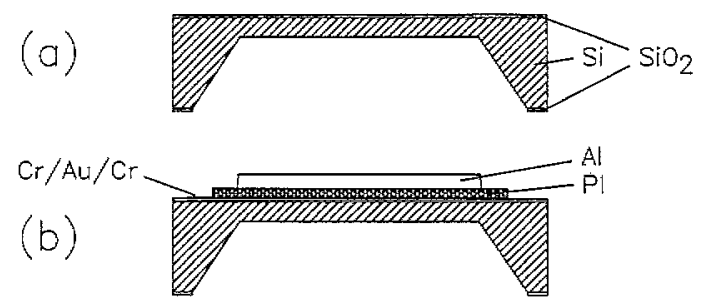

(c)

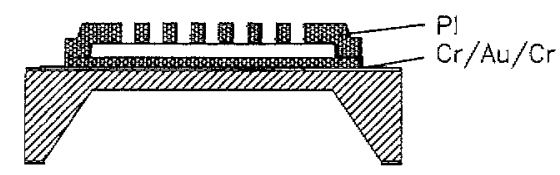

(d)

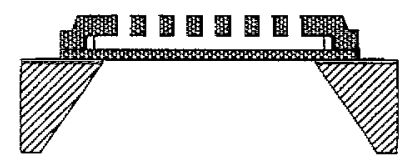

Fig. 6. Fabrication process of the microphone. 
Al etch solution. The thickness of the sacrificial layer was 1.5 $\mu \mathrm{m}$ (Fig. 6(b)).

Subsequently, the backplate electrode was deposited and patterned using resistive evaporation and lift-off. The thickness of the $\mathrm{Cr} / \mathrm{Au} / \mathrm{Cr}$ multilayer electrode was $10 / 200 / 10$ $\mathrm{nm}$. After rinsing the substrate, the polyimide backplate layer was spun on to the front using a process similar to that described for the diaphragm. However, for this layer a pure solution of the photosensitive polyimide HTR3-200 was used, and with a spin speed of $2500 \mathrm{rpm}$ for $20 \mathrm{~s}$ a layer thickness $\approx 18 \mu \mathrm{m}$ was realized after curing. The sacrificial $\mathrm{Al}$ layer was then etched for $3 \mathrm{~h}$ using the standard $\mathrm{Al}$ etch solution (Fig. 6(c)).

After rinsing, the structures were dried using a freezedrying technique, in which the substrate was first soaked in IPA for $1 \mathrm{~h}$, thereafter in cyclohexane for $30 \mathrm{~min}$, and was finally frozen in an $\mathrm{N}_{2}$ atmosphere until all of the cyclohexane was sublimated. This process, which is standard for polysilicon and silicon nitride structures, is normally used to reduce the problem of sticking in the structures. Later experiments, however, showed that the problem of sticking is much smaller for the polyimide structures than for comparable silicon nitride structures, and a simple drying of the structures by heating may therefore be applied. The final step in the fabri- cation process was to release the polyimide diaphragms by etching the remaining silicon under the diaphragm. This was done in an Electrotech PF 340 reactive ion etch reactor using an $\mathrm{SF}_{6}$ plasma with a flow of $12 \mathrm{sccm}$, a pressure of $120 \mathrm{mtorr}$ and an r.f. power of $75 \mathrm{~W}$. During the etching, the areas around the sensor were not protected, meaning that the substrate was thinned down to approximately $300 \mu \mathrm{m}$ (Fig. 6(d)). The precision of the side length of the diaphragms is determined by the thickness variation of the silicon substrate, in combination with the uniformity of the dry etch process. In the realized devices, deviations of less than $5 \%$ were measured.

With this fabrication process condenser microphones with side lengths of $1.6 \mathrm{~mm}$ (type $\mathbf{A}$ ) and $2.1 \mathrm{~mm}$ (type $\mathbf{B}$ ), have been fabricated. The SEM photograph in Fig. 7 shows the

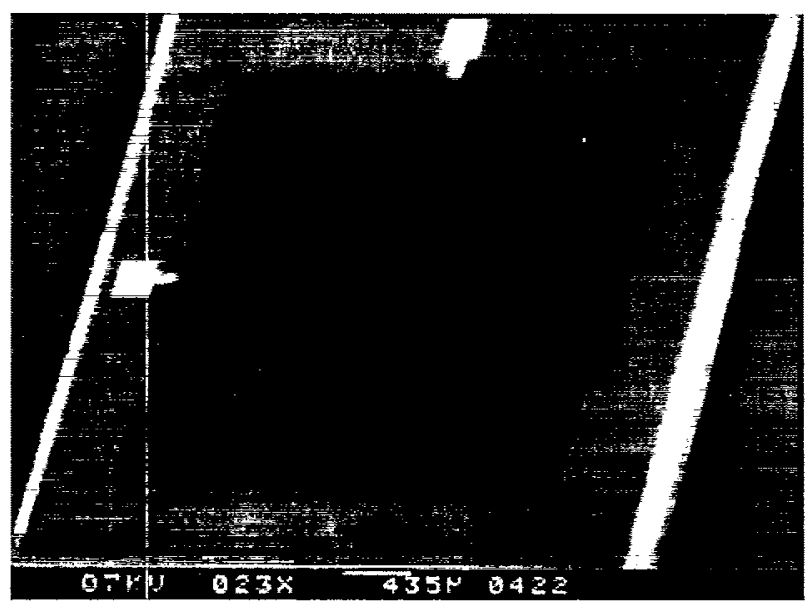

Fig. 7. SEM photograph of the front of the polyimide condenser microphone.

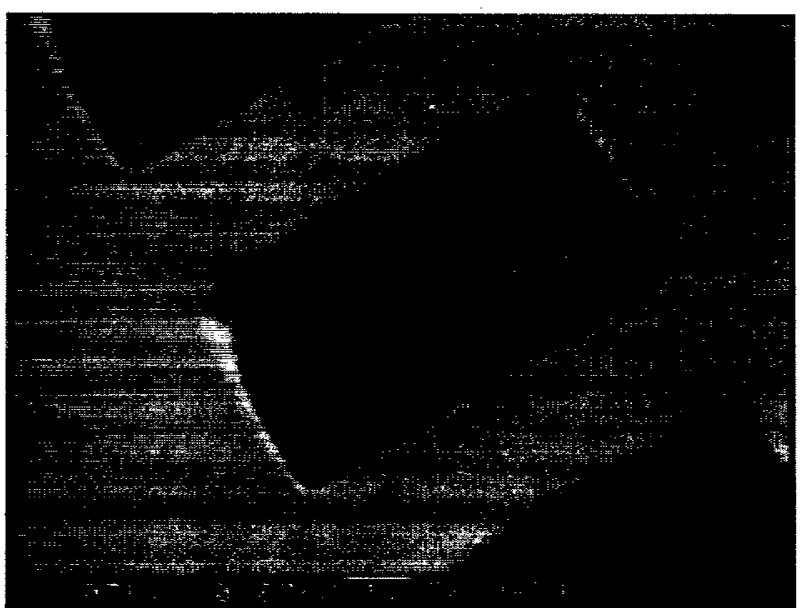

Fig. 8. Close-up SEM photograph of the polyimide backplate.

front of a completed microphone. Clearly visible are the perforated backplate and the two bond pads for electrical connection. In Fig. 8, a close-up of one of the acoustic holes is shown, and the air gap between the backplate and the polyimide diaphragm may be distinguished.

\section{Measurements and results}

For the characterization of the devices a set-up was used which allows acoustoelectric measurements to be made directly on wafer scale. This greatly improves the tumover time, since a precise acoustic measurement can be done without having to separate and mount the microphones. The acoustic set-up, which has been described in greater detail elsewhere [22], basically consists of a loudspeaker and a reference microphone. The volume inside the sealed acoustic chamber is very small, thereby allowing closed-field measurements. In the top of the chamber a small opening is made, over which one of the microphones (MUT) on the wafer under test can be placed. The electrical connections to the device are made with standard probe needles, and a small hybrid preamplifier is used to minimize the electrical loading of the connections. The set-up is controlled by a HewlettPackard 35670A Dynamic Signal Analyzer, which drives the loudspeaker and measures the output of the reference microphone and the MUT.

The acoustic measurements were done with the swept sine option with auto levelling on the HP Analyzer. In this mode the analyzer performs individual measurements at a number of frequencies within the specified frequency range, and uses the signal from the reference microphone in a feedback loop to adjust the output of the loudspeaker to the specified sound pressure. The advantage of this method over measurements with random noise is that the frequency characteristic of the loudspeaker can be compensated for, thereby ensuring the best signal-to-noise ratio in the specified frequency range. The sound pressure used in the measurements was $2 \mathrm{~Pa} \mathrm{(100}$ $\mathrm{dB}$ SPL), and the average parameters measured from four samples of each type are given in Table 2. 
Table 2

Microphone specifications

\begin{tabular}{|c|c|c|c|}
\hline & Type A & Type $\mathbf{B}$ & Conditions \\
\hline Size & $1.6 \mathrm{~mm}$ & $2.1 \mathrm{~mm}$ & \\
\hline Capacitance & $14.9 \mathrm{pF}$ & $18.5 \mathrm{pF}$ & \\
\hline Critical bias voltage & $23 \mathrm{~V}$ & $21 \mathrm{~V}$ & sound pressure: $100 \mathrm{~dB}$ SPL \\
\hline A-weighted noise voltage & $\begin{array}{l}2.5 \mu \mathrm{V}_{\mathrm{rms}} \\
5.5 \mu \mathrm{V}_{\mathrm{ms}}\end{array}$ & $25 \mu V_{\text {mins }}$ & bias voltage: $0 \mathrm{~V}$ \\
\hline & $35 \mathrm{dBA}$ SPL & $34 \mathrm{dBA}$ SPL & bias voltage: $15 \mathrm{~V}$ \\
\hline
\end{tabular}

A correction function was measured by placing a $1 / 8^{\prime \prime}$ Bruel and Kjær reference microphone (4138) over the small opening. This correction function was later used to remove effects generated by the set-up from the measured spectra. Furthermore, since the output impedance of the microphone is very high, the parasitic capacitances in the set-up will load the microphone, which reduces the measured sensitivity. To calculate the open-circuit sensitivity of the microphone, which is a more general parameter, the electrical loading must be determined. To measure this, the d.c. voltage source for the biasing of the microphone was replaced by a $100 \mathrm{mV}$ a.c. source, and the analyzer was used to measure the amplification/loading of the set-up [22]. The measured amplifications at $1 \mathrm{kHz}$ were $-10.8 \mathrm{~dB}$ for $\mathbf{A}$ and $-9.8 \mathrm{~dB}$ for $\mathbf{B}$. Furthermore, the capacitances of the microphones were determined with a Hewlett-Packard 4194A Impedance Analyzer. The measured values, $14.9 \mathrm{pF}(\mathbf{A})$ and $18.7 \mathrm{pF}(\mathbf{B})$, are in reasonable agreement with the calculated values $12.3 \mathrm{pF}(\mathbf{A})$ and $21.2 \mathrm{pF}$ (B). The differences may be explained by deviations in the height of the air gap, and residues of the $\mathrm{Al}$ sacrificial layer at the boundaries of the structure.

In Fig. 9, the corrected open-circuit frequency responses $\left(V_{\mathrm{b}}=15 \mathrm{~V}\right)$ of two microphones of the type $\mathbf{A}$ and $\mathbf{B}$ are shown. From the Figure it may be seen that open-circuit sensitivities of $-45.8 \mathrm{dBV} \mathrm{Pa}^{-1}\left(5.1 \mathrm{mV} \mathrm{Pa}^{-1}\right)$ and -41.8

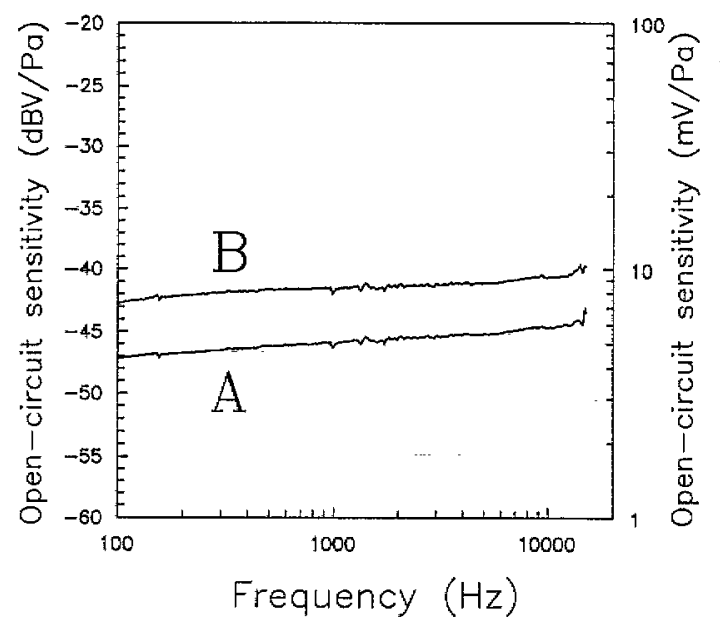

Fig. 9. Measured frequency responses of two polyimide condenser microphones (A: $1.6 \mathrm{~mm}, \mathbf{B}: 2.1 \mathrm{~mm}$ ) with $V_{\text {bias }}=15 \mathrm{~V}$.

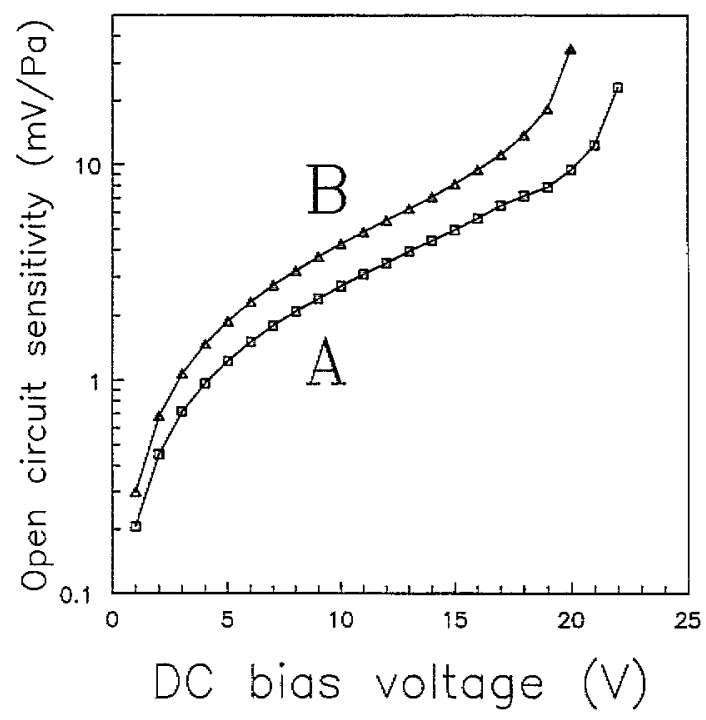

Fig. 10. Measured open-circuit sensitivity vs. d.c. bias voltage for two polyimide condenser microphones (A: $1.6 \mathrm{~mm}, \mathbf{B}: 2.1 \mathrm{~mm}$ ).

dBV $\mathrm{Pa}^{-1}\left(8.1 \mathrm{mV} \mathrm{Pa}^{-1}\right)$ were measured at $1 \mathrm{kHz}$ for $\mathbf{A}$ and $\mathbf{B}$, respectively. Furthermore, the frequency responses appear to be flat within $\pm 2 \mathrm{~dB}$ in the range between $100 \mathrm{~Hz}$ and $15 \mathrm{kHz}$. The small slope of the responses is believed to be caused by leakage from the acoustic chamber, and not by an effect in the microphones.

The stability of the microphones has been investigated for different d.c. bias voltages. In Fig. 10, the open-circuit sensitivities of $\mathbf{A}$ and $\mathbf{B}$ are plotted as a function of the bias voltage, and the critical bias voltage was measured to be $\approx 22$ $\mathrm{V}$ for $\mathbf{A}$ and $\approx 20 \mathrm{~V}$ for $\mathbf{B}$. Furthermore, experiments show that the devices are able to recover from collapse by removing the bias voltage, and since the electrodes are always insulated, the input of the preamplifier is protected against the d.c. bias voltage, even if a collapse occurs. Comparing the measurements in Fig. 9 and Fig. 10 with the simulations from Fig. 4 and Fig. 5, excellent correlation is found between the theory and the experiments.

The noise, which has previously been shown to be dominated by the preamplifier [3], was measured using a Briie] and Kjær 2610 Measuring Amplifier. The A-weighted noise at the output of the preamplifier was $-112 \mathrm{dBV}_{\mathrm{rms}}$ (2.5 $\left.\mu V_{\text {rns }}\right)$. This was measured with zero bias voltage, because 
the acoustic noise level around the set-up was not sufficiently low $(\approx 35 \mathrm{dBA}$ SPL). If the microphones are used with a d.c. bias voltage of $15 \mathrm{~V}$, the equivalent noise level is $28 \mathrm{dBA}$ SPL for $\mathbf{A}$ and $24 \mathrm{dBA}$ SPL for $\mathbf{B}$, which can be considered to be the ultimate performance.

\section{Conclusions}

In this paper, a new fabrication technology for silicon condenser microphones has been presented. The technology, which is based on the use of polyimide to create diaphragms as well as backplates, contains only low-temperature $\left(<300^{\circ} \mathrm{C}\right)$ process steps that are all in principle compatible with preprocessed integrated circuits. This means that the microphone process can be carried out on substrates on which electronic circuits have been completed. This approach proves to be flexible, because the fabrication of the microphone does not depend on the selection of the electronic circuit process, and vice versa. A remaining issue of compatibility is the etching of the substrate, which if performed with wet chemical etching (e.g., $\mathrm{KOH}$ ) will require physical protection of the electronic circuits on the substrate. This can be achieved by utilizing a special fixation during the etching, in which the front of the substrate is not in contact with the etching liquid. A different approach, which is currently being adopted, is to eliminate the wet chemical etching all together, and to etch through the substrate by means of dry etching, utilizing an anisotropic etch process [23]. In that case, no special protection of the substrate is required and the etch mask on the backside can be an evaporated metal (i.e., $\mathrm{Cr}$ ).

The use of polyimide offers some advantages, compared to existing technologies, concerning the microphone performance. First, the elastic modulus and the built-in stress are relatively low, potentially yielding diaphragms with a larger mechanical sensitivity than silicon nitride. Secondly, the polyimide layers can be made with thicknesses from $<1 \mu \mathrm{m}$ to $>30 \mu \mathrm{m}$, meaning that the backplate can be thicker than what can be made with most thin-film technologies. The performance of the realized microphones is encouraging, especially concerning the noise levels. A major reason for this is that the source capacitance of these microphones is relatively large.

The sensitivity to humidity is a well-known feature of polyimide, and is caused by absorption of water molecules in the film. This leads to a change of relative permittivity of up to $35 \%$ over the full humidity range [16]. However, assuming a $35 \%$ change of the dielectric constant in the dynamic model described above yields a change of sensitivity of less than $0.5 \mathrm{~dB}$, and may therefore be disregarded. The coefficient of thermal expansion (CTE) of conventional photosensitive polyimide is typically $40-50 \mathrm{ppm}{ }^{\circ} \mathrm{C}^{-1}$ [16], which is significantly larger than that of the silicon substrate $\left(3.2 \mathrm{ppm}{ }^{\circ} \mathrm{C}^{-1}\right)$. For increasing temperatures, the stress in the diaphragm will therefore decrease, and for a Young's modulus of the diaphragm of $3 \mathrm{GPa}$, the stress reduction will be approximately $0.25 \mathrm{MPa}{ }^{\circ} \mathrm{C}^{-1}$. A reduction of the stress leads to an increase of the microphone sensitivity, which was calculated with the dynamic model to be $2.9 \mathrm{~dB}$ for an increase from room temperature $\left(20^{\circ} \mathrm{C}\right)$ to $100^{\circ} \mathrm{C}$. The introduction of new polymides with lower CTE [24] may in the future help to improve the thermal stability of the devices.

In conclusion, it can be stated that the use of polyimide has been shown to be useful for microphones, and it is currently being applied in the fabrication of microphones on substrates containing CMOS circuits. Furthermore, investigations into other applications, such as pressure sensors and accelerometers, are being carried out, and it is believed that the technology may provide a useful alternative to the fabrication of these devices, with or without on-chip electronic circuitry.

\section{Acknowledgements}

The authors are indebted to Johan Bomer for the preparation of the samples, Bert Otter for taking the SEM photographs, and the Dutch Technical Foundation (STW) for the financial support.

\section{References}

[1] A. Kovács and A. Stoffel, Integrated condenser microphone with polysilicon electrodes, Proc. Micromechanics Europe 1995 (MME '95), Copenhagen, Denmark, 1995, pp. 132-135.

[2] J.J. Bernstein and J.T. Borenstein, A micromachined silicon condenser microphone with on-chip amplifier, Proc. Solid-State Sensor and Actuator Workshop, Hilton Head, SC, USA, 1996, pp. 239-243.

[3] A.G.H. van der Donk, J.A. Voorthuyzen and P. Bergveld, General considerations of noise in microphone preamplifiers, Sensors and Actuators A, 25-27 (1991) 515-520.

[4] D. Hohm and G. Hess, A subminiature condenser microphone with silicon nitride membrane and silicon back plate, J. Acoust. Soc. Am., 85 (1989) 476-480.

[5] J. Bergqvist and F. Rudolf, A new condenser microphone in silicon, Sensors and Actuators, A21-A23 (1990) 123-125.

[6] J. Bergqvist, F. Rudolf, J. Maisano, F. Parodi and M. Rossi, A silicon condenser microphone with a highly perforated backplate, Proc. 6th Int. Conf. Solid-State Sensors and Actuators (Trandsducers '91), San Francisco, CA, USA, 24-28 June, 1991, pp. 266-269.

[7] W. Kühnel and G. Hess, A silicon condenser microphone with structured back plate and silicon nitride membrane, Sensors and Actuators A, 30 (1992) 251-258.

[8] T. Bourouina, S. Spirkovitch, F. Baillieu and C. Vauge, A new condenser microphone with a $\mathrm{p}+$ silicon membrane, Sensors and Actuators A, 31 (1992) 149-152.

[9] J. Bergqvist and F. Rudolf, A silicon condenser microphone using bond and etch-back technology, Sensors and Actuators A, 45 (1994) $115-124$.

[10] P.R. Scheeper, A.G.H van der Donk, W. Olthuis and P. Bergveld, Fabrication of silicon condenser microphones using single wafer technology, IEEE J. Microelectromech. Syst., 1 (1992) 147-154.

[11] J. Bergqvist and J. Gobet, Capacitive microphone with a surface micromachined backplate using electroplating technology, IEEE $J$. Microelectromech. Syst., 3 (1994) 69-75.

[12] P. Horwath, A. Erlebach, R. Köhler and H. Kück, Miniature condenser microphone with a thin silicon membrane fabricated on SIMOX substrate, Tech. Digest, 8th Int. Conf. Solid-State Sensors and 
Actuators (Transducers '95/Eurosensors IX), Stockholm, Sweden, 25 29 June, 1995, Vol. 2, pp. 696-699.

[13] M.G. Allen, M. Mehregany, R.T. Howe and S.D. Senturia, Microfabricated structures for the in stitu measurement of residual stress, Young's modulus, and ultimate strain of thin films, Appl. Phys. Lett., 51 (1987) 241-243.

[14] G. Stemme, A monolithic gas flow sensor with polyimide as thermal insulator, IEEE Trans. Electron Devices, ED-33 (1986) 1470-1474.

[15] A.J. Sprenkels, R.A. Grootengel, A.J. Verloop and P. Bergveld, Development of an electret microphone in silicon, Sensors and Actuators, 17 (1989) 509-512.

[16] R.J. Jensen, J.P. Cummings and H. Vora, Copper/polyimide materials system for high performance packaging, IEEE Trans. Components, Hybrids Manufact. Technol, CHMT-7 (1984) 384-395.

[17] H.F. Olson, Acoustical Engineering, Van Nostrand, Princeton, USA, 1957, p. 71 .

[18] Z. Skvor, On the acoustical resistance due to viscous losses in the air gap of electrostatic transducers, Acustica, 19 (1967/68) 295-299.

[19] L.L. Beranek, Acoustics, McGraw-Hill, New York, USA, 1954, p. 129 and p. 135.

[20] M. Pedersen, W. Olthuis and P. Bergveld, On the mechanical behaviour of thin perforated plates and their application in silicon condenser microphones, Sensors and Actuators A, 54 (1996) 499-504.

[21] M. Pedersen, W. Olthuis and P. Bergveld, On the simulation of subminiature condenser microphones using finite differences, Proc. 1st Int. Conf. Simulation and Design of Microsystems and Microstructures (Microsim '95), Computational Mechanics Publications, ISBN: 1-85312-390-0, Southampton, UK, 1995, pp. 185-192.

[22] M. Pedersen, R. Schellin, W. Olthuis and P. Bergveld, Electroacoustical measurements of silicon microphones on wafer scale, $J$. Acoust. Soc. Am., 101 (1997) 2122-2128.

[23] R. Legtenberg, E. Berenschot, $M$. de Boer and M. Elwenspoek, Anisotropic reactive ion etching of silicon using $\mathrm{SF}_{6} / \mathrm{O}_{2} / \mathrm{CHF}_{3}$ gas mixtures, J. Electrochem. Soc., 142 (1995) 2020-2027.

[24] A.E. Nader, K. Imai, J.D. Craig, C.N. Lazaridis, D.O. Murray HI, M.T. Pottiger, S.A. Dombchik and W.J. Lautenberger, Synthesis and charaterization of a low stress photosensitive polyimide, Polymer Eng. Sci., 32 (1992) 1613-1617.

\section{Biographies}

Michael Pedersen was born in Holbæk, Denmark, on November 29, 1969. He received the M.Sc. degree in electrical engineering from the Technical University of Denmark in 1993. Currently he is working on a Ph.D. project in the Biosensor Technology Group of the MESA Institute, at the University of Twente. His research is concerned with the development of fully integrated silicon condenser microphones.

Wouter Olthuis was born in Apeldoorn, The Netherlands, on October 23, 1960. He received the M.Sc. degree in electrical engineering from the University of Twente, The Netherlands, in 1986, and the Ph.D. degree from the Biomedical Engineering Division of the faculty of Electrical Engineering, University of Twente, in 1990. Currently he is working as an assistant professor in the Biosensor Technology Group of the MESA Institute, at the University of Twente.

Piet Bergveld was born in Oosterwolde, The Netherlands, on January 26,1940 . He received the M.Sc. degree in electrical engineering from the University of Eindhoven, The Netherlands, in 1965 and the Ph.D. degree form the University of Twente, The Netherlands, in 1973. The subject of his dissertation was the development of ISFETs and related devices, the actual invention of the ISFET, since then also investigated by many international research groups of universities as well as industry. Since 1965 he has been a member of the Biomedical Engineering Division of the Faculty of Electrical Engineering (University of Twente) and was in 1984 appointed as full professor in biosensor technology. $\mathrm{He}$ is one of the project leaders in the MESA Research Institute. His research subjects still concern the further development of ISFET technology as well as physical sensors for biomedical and environmental applications, resulting up to now in more than 200 papers. 